\title{
A Simple and Efficient Method for Removal of Phenolic Contaminants in Wastewater Using Covalent Immobilized Horseradish Peroxidase
}

\author{
Rajesh Ahirwar ${ }^{1,2,6}$, Jai G. Sharma ${ }^{3}$, Bhanumati Singh ${ }^{4}$, Krishan Kumar ${ }^{5}$, Pradip Nahar ${ }^{1,2}$ and Saroj Kumar ${ }^{1,3}$ \\ 1. CSIR-Institute of Genomics and Integrative Biology, Delhi 110007, India \\ 2. Academy of Scientific and Innovative Research, CSIR-Institute of Genomics and Integrative Biology, Delhi 110007, India \\ 3. Department of Biotechnology, Delhi Technological University, Delhi 110042, India \\ 4. Department of Biotechnology, Bundelkhand University, Jhansi, UP 284128, India \\ 5. Department of Chemistry, Motilal Nehru College, University of Delhi, Delhi 110021, India \\ 6. Present address: Department of Biochemistry, ICMR-National Institute for Research in Environmental Health, Kamla Nehru \\ Hospital Building, Bhopal 462001, India
}

\begin{abstract}
In the light of the increasing burden of pollutants in major rivers and stringent environmental legislation, adaptation to eco-friendly treatment approaches is desperately required to decontaminate industrial effluents before its discharge to rivers and other fresh water-bodies. In present study, we have designed a simple and efficient method for removal of phenols from effluent wastewater using an immobilized preparation of HRP (horseradish peroxidase). The enzyme was isolated in bulk amount from the roots of the Armoracia rusticana and covalently immobilized to polycarbonate supports using a photolabile linker FNAB (1-fluoro-2-notro-4-azidobenzene). The immobilized enzyme showed enhanced storage stability and reusability. The immobilized HRP was subsequently used for degradation of phenols in sewage and spiked wastewater. The phenol content of spiked wastewater was reduced to $93 \%$ in the $3 \mathrm{~L}$ reactor following treatment with immobilized HRP and $\mathrm{H}_{2} \mathrm{O}_{2}$. The improvement in the quality of water upon treatment was reflected by the changes in $\mathrm{pH}$, conductivity, TDS (total dissolved salts) and biodegradation of organic contents as indicated by $77 \%$ and $87 \%$ reduction in COD (chemical oxygen demand) and BOD (biochemical oxygen demand) respectively in the analyzed sample.
\end{abstract}

Key words: Phenolic wastewater, enzymatic treatment, horseradish peroxidase, covalent immobilization.

\section{Introduction}

Phenolic compounds are common contaminants of water bodies connected with the industrial effluents from petrochemical, organic chemical, resins, plastic and textile industries [1-4]. Majority of phenols are toxic substances, and some are known or suspected carcinogens classified as hazardous wastes [5]. As per ISI (Indian standard institution) limits, the permissible limit of phenol/phenolic compounds in inland water resources should not cross $0.001 \mathrm{mg} / \mathrm{L}$ (permissible

\footnotetext{
Corresponding author: Saroj Kumar, Dr., young scientist, research fields: biotechnology, bionanotechnology, bioconjugation chemistry. E-mail: sarojkumar@dtu.ac.in.
}

limit in the absence of alternate source is $0.002 \mathrm{mg} / \mathrm{L}$ ). Phenol at a concentration level of as low as 0.005 $\mathrm{mg} / \mathrm{L}$ imparts a characteristic smell upon chlorination, making it unsafe for drinking purposes. The effects of phenolic compounds on humans include the irritation of nose, throat and eyes, digestive difficulties, nervous problems, headaches and skin burns. Prolonged ingestion of phenol at concentration levels ranging 10-240 $\mathrm{mg} / \mathrm{L}$ can cause mouth sore, diarrhea and impaired vision [5]. The industrial effluents, which may contaminate the rivers and other water resources, carry phenolic content in the range of 200 to 2,000 $\mathrm{mg} / \mathrm{L}$. If released untreated to rivers, this large 
concentration of phenols in wastewater can cause enormous damage to both the aquatic and human lives. Therefore, removal of phenol and its derivatives from contaminated water before discharge into river or other water bodies is strongly recommended to save aquatic organisms and preserve the environmental quality [6,7]. Various conventional methods have been applied to remove phenols from wastewater including steam distillation, liquid-liquid extraction, adsorption, solid-phase extraction, wet air oxidation, catalytic wet air oxidation and biodegradation [8]. With further advancement in technologies, newer methods like electrochemical oxidation, photo-oxidation, coronation, $\mathrm{UV} / \mathrm{H}_{2} \mathrm{O}_{2}, \quad$ Fenton reaction, membrane processes and enzymatic treatment have been used for phenol degradation [2-4, 9, 10]. Still, many of these methods have disadvantages like low efficiency, high cost, partial removal and formation of hazardous by-products [11-13]. Hence, the need to develop an efficient, simple and scalable method for removal of phenolic contaminants from wastewater still persist. Enzymes such as peroxidases obtained from horseradish, soybean and other plant sources have been used to remove phenols from waste effluents in the presence of hydrogen peroxide [14-17]. In presence of $\mathrm{H}_{2} \mathrm{O}_{2}$, the native HRP (horseradish peroxidase) is oxidized to an active intermediate (HRPi) that catalyzes oxidation of aromatic compounds, producing a free radical $(\mathrm{AH} \bullet)$ and returns to its native state (HRP). The released free radicals, in bulk solution, form polyaromatic products, which are water-insoluble and remove as precipitate $[9,17,19]$. As shown in the following reaction steps Eqs. (1)-(3).

$$
\begin{gathered}
\mathrm{HRP}+\mathrm{H}_{2} \mathrm{O}_{2} \rightarrow \mathrm{HRPi}+\mathrm{H}_{2} \mathrm{O} \\
\mathrm{HRPi}+\text { Aromatic compound }\left(\mathrm{AH}_{2}\right) \rightarrow \\
\text { HRPii }+ \text { Free Radical }(\mathrm{AH} \bullet) \\
\text { HRPii }+ \text { Aromatic compound }\left(\mathrm{AH}_{2}\right) \rightarrow \\
\mathrm{HRP}+\text { Free Radical }(\mathrm{AH} \bullet)+\mathrm{H}_{2} \mathrm{O}
\end{gathered}
$$

The major issue with peroxidases is the reduction in phenol removal efficiency at low concentrations of the enzyme due to the inactivation of the enzyme. Use of higher concentrations of purified enzyme can lead to tremendous increase in capital investment for bulk purification facility. Also, the separation of enzyme from treated water is not possible without its immobilization on some solid supports [20]. As the immobilization of enzymes may solve such limitations, several approaches for covalent and non-covalent immobilization of peroxidase enzyme to solid matrices are reported in the literatures [21-25]. The covalent approach is usually preferred as that it restricts the loss of enzyme, allowing more enzymes per unit amount of degradable phenolic contaminants.

To develop a simple and scalable method for enzymatic removal of phenolic contaminants from wastewater effluents, we have immobilized HRP on PC (polycarbonate) discs and used it to degrade the phenolic contaminants in sewage water. Further, the effect of PEG (polyethylene glycol) addition on HRP activity during dephenolization was studied. Finally, the immobilized preparation of HRP was used in a lab-made wastewater treatment cell (bioreactor; $3 \mathrm{~L}$ capacity) to study its effectiveness in lowering the phenolic contaminants in the collected sewage wastewater samples. A comparison of treated and untreated wastewater was made in terms of change in physical parameters like $\mathrm{pH}$, salinity, conductivity, TDS (total dissolved salts) and chemical parameters including residual phenolic contaminants, ammonia $\left(\mathrm{NH}_{3}\right)$, sodium $\left(\mathrm{Na}^{+}\right)$and chloride $\left(\mathrm{Cl}^{-}\right)$ions, nitrates $\left(\mathrm{NO}_{3}{ }^{-}\right)$and nitrites $\left(\mathrm{NO}_{2}{ }^{-}\right)$, BOD (biochemical oxygen demand) and COD (chemical oxygen demand).

\section{Experimental Setup}

\subsection{Chemicals and Reagents}

Phenol, p-chlorophenol, potassium ferricyanide, 4-aminoantipyrine (4-AAP), ammonium sulphate, polyethylene glycol (PEG; average molecular weight 3,350) were purchased from SRL (scientific research laboratory), India Pvt Ltd. Hydrogen peroxide $\left(\mathrm{H}_{2} \mathrm{O}_{2}\right.$; $30 \%, \mathrm{v} / \mathrm{v})$, was purchased from Merck Life Science 
Pvt. Ltd. Bengaluru, India. Photolinker FNAB was synthesized using 4-fluoro-3-nitroaniline (Sigma-Aldrich, Germany) as reported earlier in Ref. [26]. Photo irradiation of polycarbonate discs was carried out at a wavelength of $365 \mathrm{~nm}$ in a UV Stratalinker, model-2400, (Stratagene, USA). Polycarbonate sheets were purchased from the local market (New Delhi, India). All the experiments were carried out in triplicates. The absorbance of samples was recorded in an ELISA reader (BioRad laboratories India).

\subsection{Isolation and Purification of HRP}

Horseradish peroxidase was isolated and purified from the roots of horseradish (Armoracia rusticana) according to previously reported procedure [27]. Briefly, the roots of horseradish were crushed to collect the homogenate. Crude HRP was obtained from the collected homogenate using ammonium sulphate precipitation (90\% saturation) and dialysed in $5 \mathrm{mM}$ acetate buffer $(\mathrm{pH}$ 4.4) for overnight. Next, the collected crude enzyme was fractioned on an ion exchange column (Whatman's carboxymethylcellulose CM52) to obtain partially purified enzyme. Further purification was carried out using size-exclusion chromatography on HiPrep Sephacryl S-100 HR column (GE Healthcare Life Science, India).

\subsection{Measurement of HRP Activity}

Measurement of HRP activity is based on the mechanism of HRP action. HRP combines with $\mathrm{H}_{2} \mathrm{O}_{2}$ (hydrogen peroxide) to form an intermediate HRP- $\mathrm{H}_{2} \mathrm{O}_{2}$ complex, which can oxidize a wide variety of hydrogen donors.

Donor $+\mathrm{H}_{2} \mathrm{O}_{2} \rightarrow$ Oxidized Donor $+2 \mathrm{H}_{2} \mathrm{O}$

We measured the enzyme activity of the purified HRP using modified Worthington method [28]. During the HRP biocatalysis, the hydrogen donor couple phenol/4-aminoantipyrine was converted to a pink-coloured reagent with maximum absorption $\left(\lambda_{\max }\right)$ at $510 \mathrm{~nm}$, which was used in the assay of HRP activity. Briefly, the method involves incubation of $0.1 \mathrm{~mL}$ of HRP (in $0.1 \mathrm{M}$ phosphate buffer, $\mathrm{pH} 7.0$ ) with $1.5 \mathrm{~mL}$ of $0.17 \mathrm{mM} \mathrm{H}_{2} \mathrm{O}_{2}$ (in $0.1 \mathrm{M}$ phosphate buffer, $\mathrm{pH}$ 7.0) and $1.4 \mathrm{~mL}$ of phenol/ 4-aminoantipyrine solution $(0.17 \mathrm{M}$ phenol with 2.5 $\mathrm{mM}$ 4-AAP in MilliQ water) for 1-5 minutes of time period. Increase in absorbance $(\lambda=510 \mathrm{~nm})$ was recorded at different time points during the 1-5 min incubation period. One unit of HRP activity (U) is defined as the amount of HRP required to hydrolyze 1 $\mu \mathrm{mol}$ of $\mathrm{H}_{2} \mathrm{O}_{2}$ in 1 min at $25^{\circ} \mathrm{C}$ and $\mathrm{pH}$ 7.0. Specific activity can be calculated as unit activity per mg HRP.

Unit activity was measured as:

$$
U / m L=\frac{(\Delta A 510 / \text { mintest }-\Delta A 510 / \text { mincontro }) \times 3 \times d f}{\varepsilon \times 0.1}
$$

where 3 is the total volume of assay solution, $0.1 \mathrm{~mL}$ is the volume of enzyme and $\mathrm{df}$ is the dilution factor. The molar extinction coefficient $(\mathcal{E})$ of chromogenic dye (phenol/4-aminoantipyrine solution) is $7,100 / \mathrm{M}$ cm [29].

\subsection{Activation of Polycarbonate Disc}

Circular polycarbonate discs (total surface area $=$ 50-180 $\mathrm{cm}^{2}$ ) were prepared for covalent immobilization of HRP by covering them with the ethanolic solution of FNAB (1.82 mg FNAB per 30 $\mu \mathrm{L}$ ethanol) followed by the evaporation of ethanol in a dark fume hood to form a layer of FNAB over the PC discs. The discs were then irradiated with UV light at $365 \mathrm{~nm}$ in a UV-Stratalinker for $15 \mathrm{~min}$ [30]. After this, the unreacted FNAB on PC-discs was removed by ethanol wash and the discs were air-dried to get the FNAB activated disc ready for covalent immobilization.

\subsection{Immobilization of HRP onto Activated Polycarbonate Discs}

The activated PC discs were taken in petri dishes and loaded with different amounts $(0.25-4 \mathrm{U} / \mathrm{mL})$ of HRP in phosphate-buffered saline (0.1 M PBS, pH 7.0). Immobilization was carried out in a laboratory 
incubator by $45 \mathrm{~min}$ incubation at $50{ }^{\circ} \mathrm{C}$. After incubation, the discs were washed with washing buffer (0.1 M PBS, pH 7.0 with $0.1 \%$ Tween 20$)$ and stored at $4{ }^{\circ} \mathrm{C}$. The unbound HRP from activated PC discs was collected to determine the immobilization capacity and the concentration of residual HRP in solution was determined by the method of bicinchoninic acid [31]. The amount of the immobilized enzyme was calculated as:

$$
Q=\frac{\left(C_{0}-C\right) V}{A}
$$

where, Q is the amount of HRP immobilized per unit area of polycarbonate discs $\left(\mathrm{mg} / \mathrm{cm}^{2}\right), C_{0}$ and $C$ are the concentrations $(\mathrm{mg} / \mathrm{mL})$ of HRP before and after the immobilization. $V$ is the volume of the used HRP solution, and $A$ is the surface area of the polycarbonate discs.

\subsection{Effect of $\mathrm{pH}$ and Temperature on the Activity of Immobilized HRP}

The activity of immobilized and free HRP was checked at different $\mathrm{pH}$ (3 to 6 in $0.1 \mathrm{M}$ citrate-phosphate buffer and 7 to 9 in $0.1 \mathrm{M}$ phosphate buffer). The effect of temperature on the enzymatic activity of immobilized and free HRP was determined by measuring the residual activity after $60 \mathrm{~min}$ incubation in $0.1 \mathrm{M}$ phosphate buffer, $\mathrm{pH} 7.0$ at various temperatures $\left(27^{\circ} \mathrm{C}-60^{\circ} \mathrm{C}\right)$.

\subsection{Degradation of the Phenolic Compounds in Spiked MilliQ Using PC-HRP}

Oxidative degradation of phenol and p-chlorophenol using the immobilized HRP was studied in petri dishes containing $2 \mathrm{~mL}$ of $128 \mathrm{mg} / \mathrm{L}$ phenolic mixture (in MilliQ water) and PC-HRP disc (total surface area $=48 \mathrm{~cm}^{2}$ ) in $7.75 \mathrm{~mL}$ of $0.1 \mathrm{M}$ PBS, pH 7.0. The enzymatic reaction was initiated by adding $0.25 \mathrm{~mL}$ of $10 \mathrm{mM} \mathrm{H} \mathrm{H}_{2} \mathrm{O}_{2}$ after which the assembly was incubated for $3 \mathrm{~h}$ at room temperature. Degradation of phenolic compounds was monitored by withdrawing $200 \mu \mathrm{L}$ aliquots from the reaction mixture and estimating the residual phenols by the colorimetric method as reported earlier [32]. Briefly, the assay was carried out by mixing $200 \mu \mathrm{L}$ of collected phenolic sample with $25 \mu \mathrm{L}$ of $83.4 \mathrm{mM}$ $\mathrm{K}_{3} \mathrm{Fe}(\mathrm{CN})_{6}$ (in $\mathrm{NaHCO}_{3}$ ) and $25 \mu \mathrm{L}$ of $20.8 \mathrm{mM}$ of 4-aminoantipyrine (in $0.25 \mathrm{M} \mathrm{NaHCO}_{3}$ ). The reaction was incubated for 2-5 min, after which the absorbance was measured at $510 \mathrm{~nm}$. The absorbance units provide an estimate of the non-degraded phenols.

Also, the protective effect of PEG on the enzymatic activity of immobilized HRP during dephenolization was studied. For this, the PC-HRP discs (total surface area $=48 \mathrm{~cm}^{2}$ ) were loaded with $10 \mathrm{~mL}$ solution of the prepared phenol contaminated water $(64 \mathrm{mg} / \mathrm{L}$ of each phenol and p-chlorophenol in MilliQ water) and incubated in presence of different amount of PEG $(0.25,0.5,1.0$, and $2.0 \mathrm{mg} / \mathrm{mL})$ for $3 \mathrm{~h}$ at room temperature. After stipulated time, the residual phenol in each sample was measured and plotted as relative activity (HRP) against PEG concentrations.

\subsection{Degradation of the Phenolic Compounds in Sewage Wastewater Using PC-HRP}

An assembly for enzymatic degradation of phenolic contaminants in sewage water was prepared by attaching the HRP-immobilized PC-discs to a rod (shaft) fitted to an inverted mixer. The rod along with its inverted-mixer was mounted in a glass beaker of 3 L capacity. The beaker was filled with sewage water collected from the local drain (Najafgarh Drain; collection point- Kingsway Camp, Delhi, India). The enzymatic reaction was initiated by adding $\mathrm{H}_{2} \mathrm{O}_{2}$ to a final concentration of $0.25 \mathrm{mM}$. This followed the addition of optimised concentration of PEG. The sample was kept stirring (100-120 RPM) with the help of fitted PC-HRP discs. Total phenol in sewage wastewater before and after treatment (at $1 \mathrm{~h}, 2 \mathrm{~h}, 3 \mathrm{~h}$ and $14 \mathrm{~h}$ intervals) was measured using the colorimetric method [32]. Various physiological and chemical parameters of the collected sewage water 

Wastewater Using Covalent Immobilized Horseradish Peroxidase

like the $\mathrm{pH}$, total dissolved salts, conductivity, salinity, phenolic contaminants, ammonia $\left(\mathrm{NH}_{3}\right)$, sodium ion $\left(\mathrm{Na}^{+}\right)$, chloride ion $\left(\mathrm{Cl}^{-}\right)$, nitrates $\left(\mathrm{NO}_{3}{ }^{-}\right)$ and nitrites $\left(\mathrm{NO}_{2}{ }^{-}\right), \mathrm{BOD}$ and $\mathrm{COD}$ were also measured before and after treatment. Total dissolved salts, pH, salinity and conductivity measurements were performed on Seven Excellence ${ }^{\mathrm{TM}}$ $\mathrm{pH} /$ conductivity/ion meter (model- S400, METTLER TOLEDO, Switzerland). The nitrates and nitrites were detected using the spectrophotometric method as reported elsewhere shown in Ref. [33]. Determination of ammonia was performed using the Orion AQUAfast AC4010 ammonia ultra low range auto-test ampoules with the Orion AQUAfast AQ4000 colorimeter (Thermo Scientific). Analysis of sodium and chlorine was made using kits availed from $\mathrm{HACH}$, USA. BOD and COD measurements were performed as per "Standard Analytical Procedures for Water Analysis" set up by Central Water Commission, Govt. of India [34].

\subsection{Reusability and Storage Stability of Immobilized HRP}

The reusability of PC-immobilized HRP for phenolic degradation was investigated in a $3 \mathrm{~L}$ bioreactor. During each reusability experiment, the bioreactor system was operated for $2 \mathrm{~h}$. The storage stability of immobilized HRP was determined after 0 , 2, 4, 8 and 16 days storage in a sealed polyethylene bag in a refrigerator at $4{ }^{\circ} \mathrm{C}$. The activity of immobilized HRP was expressed as percentage of its residual activity with respect to their initial activity.

\section{Results and Discussion}

\subsection{Preparation of HRP Immobilized PC-discs}

We have isolated and purified HRP enzyme from the roots of Armoracia rusticana using a low-cost setup. A yield of $80 \mathrm{mg}$ purified HRP was obtained from $1 \mathrm{Kg}$ horseradish (Fig. 1). The calculated specific activity of the purified lyophilized HRP obtained after ion-exchange and size exclusion chromatography was $100 \mathrm{U} / \mathrm{mg}$. The polycarbonate discs for covalent immobilization of HRP were prepared by activating their surfaces using an aryl azide-based heterobifunctional crosslinker, FNAB. The linker coated discs were exposed to UV light to generate highly reactive nitrene, which attaches covalently to PC surface through $\mathrm{C}-\mathrm{H}$ bond insertion $[26,35]$. This activated polycarbonate having an active fluoro group enables bio-conjugation of HRP through the amino group of the enzyme when incubated at an elevated temperature of $40-50{ }^{\circ} \mathrm{C}$ [36].

Further, we determined the immobilization capacity of HRP over PC discs by measuring the residual protein in left over unreacted HRP collected from immobilization experiments in which varying concentrations $(0.25,0.5,1,2,4 \mathrm{U} / \mathrm{mL})$ of HRP (specific activity $=100 \mathrm{U} / \mathrm{mg}$ ) were immobilized onto the activated PC discs (total surface area $=1 \mathrm{~cm}^{2}$ ). The immobilization capacities were calculated using Eq. (6). An optimal immobilization of $1.0 \mathrm{U} / \mathrm{cm}^{2}$ was achieved. This suggests a PC disc of radius 1 meter would require $3.14 \mathrm{mg}$ purified HRP (sp. Activity = $100 \mathrm{U} / \mathrm{mg}$ ), which is considerably a cost-effective amount of enzyme.

Furthermore, the enzymatic degradation of o-phenylenediamine by the PC-HRP discs showed that HRP retain its enzymatic activity after immobilization (a)

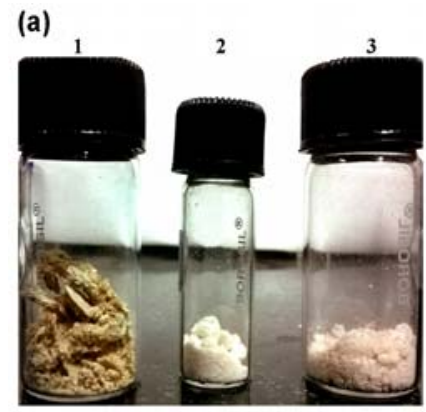

(b)

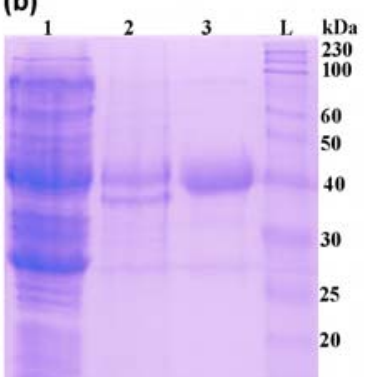

Fig. 1 Isolation and purification of HRP from the roots of horseradish. (a) Crude HRP a1 is obtained from horseradish homogenate after ammonium precipitation and purified on ion-exchange a2 and size-exclusion a3 columns. (b) SDS PAGE of HRP in its crude form (lane 1), after ion-exchange chromatography (lane 2) and after size-exclusion chromatography (lane 3 ). $L$ represents the pre-stained protein ladder of size 10-230 kDa (NEB). 
(Fig. 2). Control assay performed with untreated PC discs carrying physically adsorbed HRP produced an insignificant absorbance reads, suggesting an absolute requirement of chemical linkers for enzyme immobilization onto PC discs. Polycarbonate was taken as model support for enzyme immobilization because of its stability (both thermal and mechanical) and chemical inertness.

\subsection{Optimizing the Reaction Parameters for Maximum} Activity of the Immobilized HRP

The effect of $\mathrm{pH}$ on the activity of free and immobilized HRP was studied at $\mathrm{pH}$ 3-9. Citrate-phosphate buffer, $0.1 \mathrm{M}$ was used to study the effect of $\mathrm{pH}$ in the range of 3-6, while phosphate buffer, $0.1 \mathrm{M}$ was used for $\mathrm{pH}$ of 7-9. As shown in Fig. 3a, the maximum relative activity of immobilized and free enzyme was obtained at $\mathrm{pH}$ 7.0. Nevertheless, at any $\mathrm{pH}$ (except pH 7.0), the relative activity of immobilized HRP has remained higher than the free enzyme. This broadening in the $\mathrm{pH}$ profile of HRP upon immobilization could be explained by change in charge interactions upon formation of strong covalent bond between surface and enzyme [37, 38].

Similarly, the thermal stability of the immobilized and free HRP was determined by incubating them in PBS (0.1 M PBS, pH 7.0) for $60 \mathrm{~min}$ at $27^{\circ} \mathrm{C}, 40^{\circ} \mathrm{C}$, $45{ }^{\circ} \mathrm{C}, 50{ }^{\circ} \mathrm{C}, 55{ }^{\circ} \mathrm{C}$ and $60{ }^{\circ} \mathrm{C}$, respectively. The residual activity of immobilized and free HRP was calculated with respect to its initial activity at room temperature of $27^{\circ} \mathrm{C}$. As shown in Fig. 3b, both the

(a)

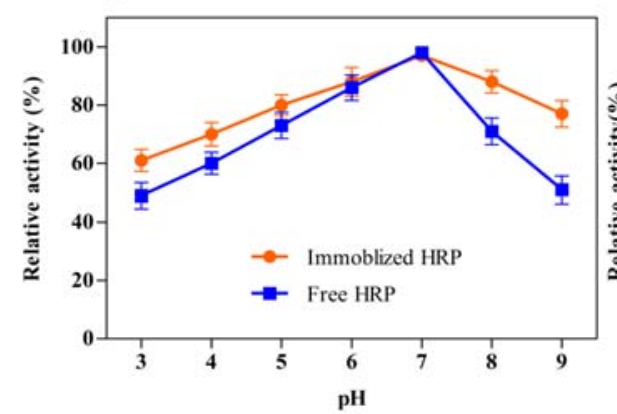

immobilized and free enzyme retained similar activity at low temperatures of up to $50{ }^{\circ} \mathrm{C}$, beyond which the activity of both immobilized and free HRP got decreased with increasing temperature. As expected, it was found that the PC-immobilized HRP retained approx $89 \%$ of its initial activity after $60 \mathrm{~min}$ incubation at $60{ }^{\circ} \mathrm{C}$, whereas free enzyme retained only $73 \%$ of its initial activity at corresponding time and temperature. This suggests that the enzymatic activity and stability of HRP improve upon immobilization onto PC discs. Increase in thermal stability of HRP upon immobilization could be contributed to the same strong interactions between enzyme and support that affect the intra-molecular forces responsible for maintaining the conformation,

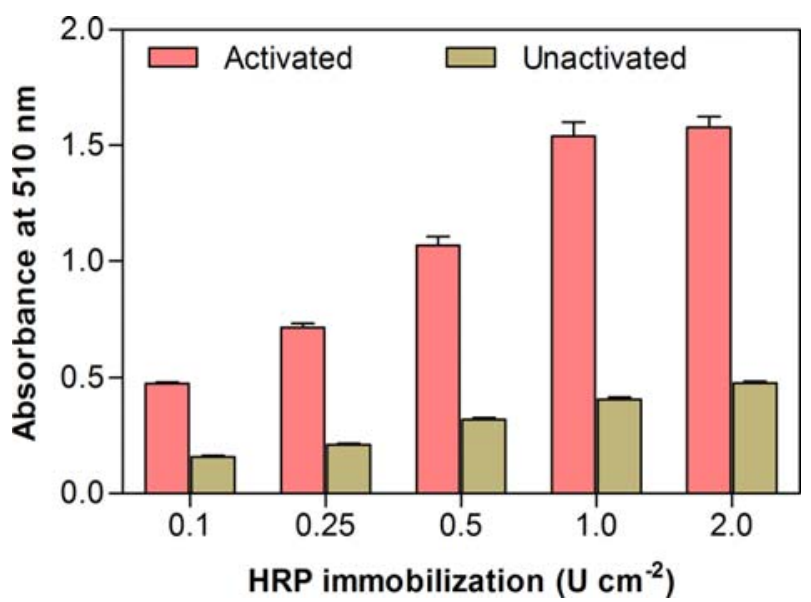

Fig. 2 Analysing the activity of immobilized HRP. Enzymatic conversion of colourless o-phenylenediamine (dihydrochloride) solution to an orange-brown coloured product using physically adsorb (un-activated) and chemically (using FNAB; activated) immobilized HRP on PC discs.

(b)

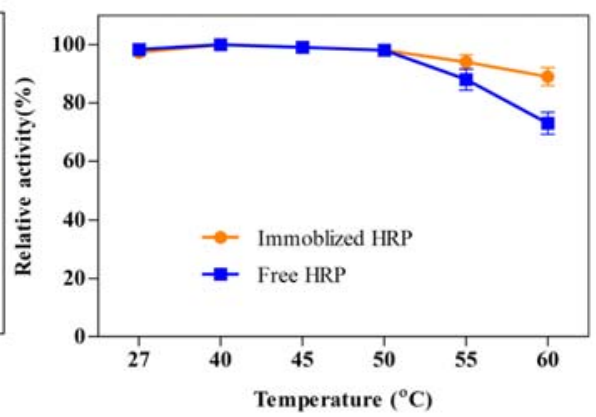

Fig. 3 (a) Effect of $\mathrm{pH}$ on the relative activity (against standard pH 7.4) of the immobilized and free HRP. (b) Effect of temperature on the relative activity (against standard temperature $27^{\circ} \mathrm{C} \pm 2^{\circ} \mathrm{C}$ ) of immobilized and free HRP. 
thus the activity of the enzyme [39]. The observation of increased thermal stability and broader $\mathrm{pH}$ range upon immobilization imprints the idea of using PC-HRP in industrial setup.

\subsection{Efficient Removal of Phenol and p-chlorophenol from Spiked MilliQ Water}

To test the capacity of the developed PC-HRP system to remove phenols from water samples, we added $64 \mathrm{mg} / \mathrm{L}$ phenol and $64 \mathrm{mg} / \mathrm{L}$ p-chlorophenol to MilliQ water. The enzymatic degradation of phenols was studied at different time points; the PC-HRP disc with total surface area of $48 \mathrm{~cm}^{2}\left(1.0 \mathrm{U} / \mathrm{cm}^{2}\right)$ degraded $80 \%$ phenols in first $30 \mathrm{~min}, 94 \%$ in $60 \mathrm{~min}$ and $96 \%$ phenols upon $3 \mathrm{~h}$ incubation (Fig. 4a). Like previous observations of $90 \%$ phenol degradation using purified HRP, we achieved an efficiency of $96 \%$ polymerization using the immobilized HRP $[19,40$, 41].

The efficiency of phenol reduction can be enhanced by either increasing the enzyme concentration or by increasing the incubation time. However, longer incubations can result in enzyme inactivation, leading to low conversion [42]. Previous reports suggest that the presence of additives such as PEG enhance enzyme performance for the treatment of wastewater containing a range of phenol concentrations between 47-1,500 mg/L [43]. Accordingly, we used additive PEG $(0-2 \mathrm{mg} / \mathrm{mL})$ for its protective action on HRP

(a)

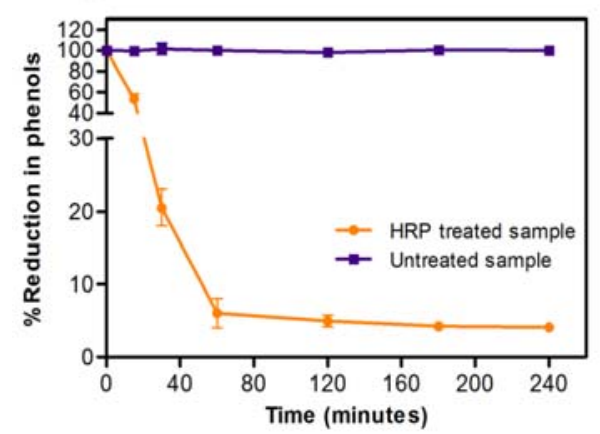

during removal of phenol and p-chlorophenol. As shown in Fig. 4 b, the HRP retains $93 \%$ of its initial activity in the presence of PEG at an optimal concentration of $1 \mathrm{mg} / \mathrm{mL}$ after $3 \mathrm{~h}$ incubation in the spiked phenolic water $(128 \mathrm{mg} / \mathrm{L}$ phenols $)$. Whereas, only 35\% HRP activity was monitored in samples carrying no PEG. In HRP-catalysed phenolic reactions, the HRP inactivation mainly occurs as a result of sorption/occlusion by polymeric products (HRP adsorption on precipitated products occludes its active sites) [44] or upon heme-destruction (generated free radicals react and inactivate the heme-centre in HRP) [45]. This improvement in the efficiency of HRP by PEG addition during dephenolization is due to the formation of a protective layer in the vicinity of the active centre of HRP which restricts the attack of free phenoxy radicals and help in effectively suppressing the heme-destruction by co-dissolved PEG [44-46].

\subsection{Removal of Phenolic Contaminants from Sewage Wastewater}

The removal of phenolic contaminants from the collected sewage wastewater was performed in a $3 \mathrm{~L}$ glass beaker assembly as shown in Fig. 5. Due to lack of open sites of discharge of industrial effluents in Delhi, we have used water samples collected from local drain, which majorly contains the household sewage. Before and after treatment analysis of collected wastewater showed $91 \%$ reduction in phenolic

(b)

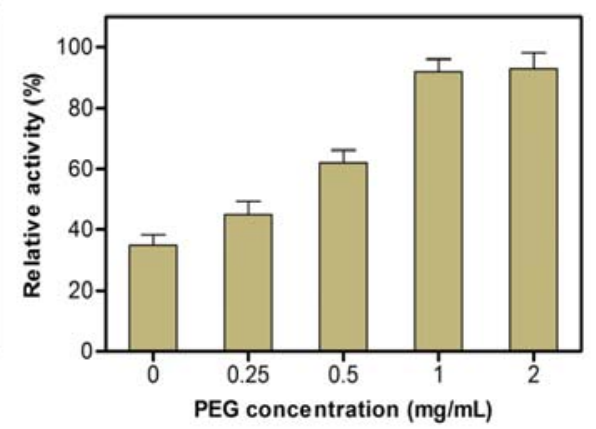

Fig. 4 Optimization of parameters for removal of phenolic contaminants from spiked water. (a) Time-dependent removal of phenol and p-chlorophenol from spiked water carrying total $128 \mathrm{mg} / \mathrm{L}$-of phenols using PC-HRP disc. (b) Optimization of PEG concentrations for removal of p-chlorophenol from contaminated water. 

Wastewater Using Covalent Immobilized Horseradish Peroxidase
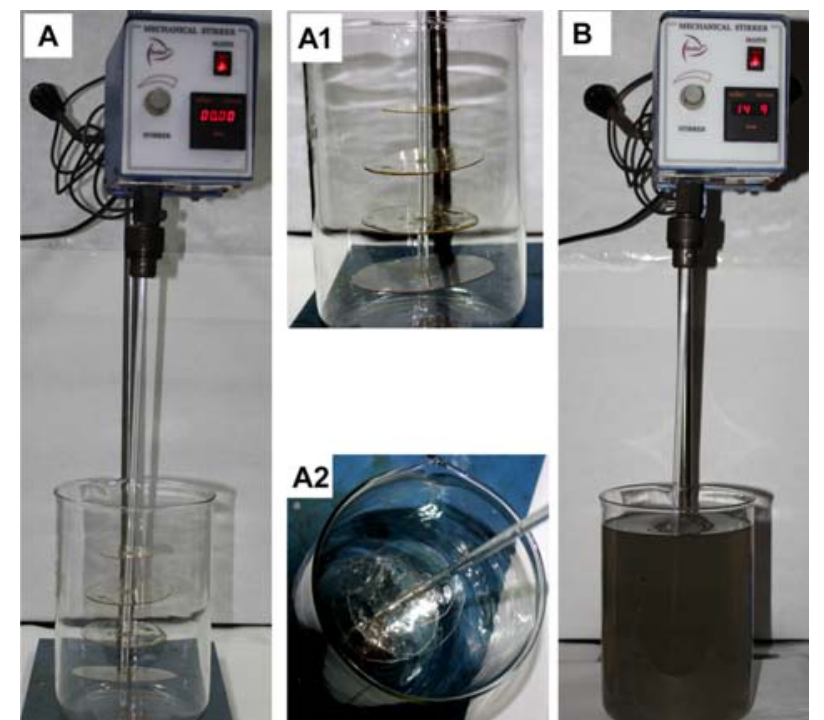

Fig. 5 Setup to remove phenols from contaminated wastewater. (A) The prepared empty assembly showing the PC-HRP disc attached to turbine of inverted rotor. A1 and A2 provide a close-up image of the turbine created using PC-HRP discs. (B) Phenol removal assembly with filled sewage water. Phenol degradation is initiated by adding $0.25 \mathrm{mM} \mathrm{H}_{2} \mathrm{O}_{2}$ to the filled effluent tank. The PC-HRP discs are rotated at a constant speed of $100-120 \mathrm{rpm}$ to prevent settlement of added PEG (1 g/L). Samples are collected at 1 , 2,3 , and $14 \mathrm{~h}$ intervals to monitor phenol degradation. content. The initial concentration of phenols in the collected wastewater sample was calculated to 2-3 $\mathrm{mg} / \mathrm{L}$. As the collected wastewater majorly contains the household sewage, such a low amount of phenolic contamination was expected. Interestingly, after $3 \mathrm{~h}$ of oxidative degradation by PC-HRP, the phenolic contamination has reduced to $0.22 \mathrm{mg} / \mathrm{L}$. Because the collected wastewater had low level of phenolic contaminants, to obtain an ideal sample for analysis, we have added phenol (10 mg/L), p-chlorophenol (10 $\mathrm{mg} / \mathrm{L}$ ), 2, 4-dichlorophenol (5 mg/L), catechol and 2, 4-dimethylphenol ( $5 \mathrm{mg} / \mathrm{L})$ to a total concentration of $30 \mathrm{mg} / \mathrm{L}$ phenols in the collected wastewater sample. Enzymatic treatment of this spiked wastewater using the prepared assembly of PC-HRP resulted in phenol reduction by $81 \%$ in $1 \mathrm{~h}$ treatment, which further reduced to $93 \%$ in $2 \mathrm{~h}$ and $95 \%$ upon $3 \mathrm{~h}$ of treatment (Table 1). A further increase in the incubation time (e.g. overnight) showed no further reduction in phenolic contaminants. The improvement in the quality of water upon treatment

Table 1 Degradation of phenols in spiked sewage wastewater using PC-HRP discs.

\begin{tabular}{lll}
\hline Time $(\mathrm{h})$ & Concentration of phenolic contaminants $(\mathrm{mg} / \mathrm{L})$ & Percentage reduction in phenols \\
\hline 0 & $30.09 \pm 0.18$ & 0 \\
1 & $5.64 \pm 0.03$ & 81 \\
2 & $2.11 \pm 0.11$ & 93 \\
3 & $1.49 \pm 0.27$ & 95 \\
\hline
\end{tabular}

This sample was spiked sewage wastewater. The 0-hour sample is the untreated wastewater. Concentrations of phenols are calculated from a standard graph prepared using the colorimetric method of phenol determination.

Table 2 Physical and chemical analysis of the treated and untreated spiked sewage wastewater.

\begin{tabular}{lll}
\hline Sample parameter & Untreated sewage water & PC-HRP treated sewage water \\
\hline $\mathrm{pH}$ & $7.0 \pm 0.2$ & $7.9 \pm 0.1$ \\
$\mathrm{TDS}\left(\mathrm{mg} \mathrm{L}^{-1}\right)$ & $880.5 \pm 25$ & $665.6 \pm 12$ \\
Conductivity $\left(\mu \mathrm{S} \mathrm{cm}^{-1}\right)$ & $2207 \pm 110$ & $1667 \pm 70$ \\
Salinity $(\mathrm{psu})$ & $1.13 \pm 0.08$ & $0.84 \pm 0.04$ \\
Ammonia $(\mathrm{ppm})$ & $27.2 \pm 0.7$ & $12.0 \pm 0.8$ \\
$\mathrm{Na}^{+} / \mathrm{Cl}^{-}(\mathrm{mg} / \mathrm{L} ; \mathrm{mV})$ & $238 \pm 20 ; 15.6 \pm 1.3$ & $166 \pm 20 ; 6.4 \pm 1.0$ \\
$\mathrm{Nitrite}^{-} \mathrm{NO}_{2}^{-}(\mathrm{mg} / \mathrm{L})$ & $1.08 \pm 0.1$ & $0.85 \pm 0.1$ \\
Nitrate, $\mathrm{NO}_{3}^{-}(\mathrm{ng} / \mathrm{L})$ & $0.16 \pm 0.03$ & $0.07 \pm 0.02$ \\
$\mathrm{BOD}(\mathrm{mg} / \mathrm{L})$ & $208 \pm 26$ & $26 \pm 6$ \\
$\mathrm{COD}(\mathrm{mg} / \mathrm{L})$ & $620 \pm 45$ & $140 \pm 18$ \\
\hline
\end{tabular}

This sample was spiked sewage wastewater $(30 \mathrm{mg} / \mathrm{L}$ phenols $)$. 
was reflected by the changes in the physical (optical density, $\mathrm{pH}$, TDS, conductivity, salinity) and chemical (ammonia, nitrates, nitrites, BOD, COD) properties of the water (Table 2). The increase in $\mathrm{pH}$ or the amount of negative hydroxide ions results in bond formation with the positively charged heavy metal ions present in the wastewater. This creates a dense, insoluble precipitate of metal particles that settle out of wastewater after a given time. The precipitate entraps other particulate matter and salts, resulting in reduced TDS content, conductivity and salinity of wastewater upon treatment. The reduction in the content of ammonia in wastewater after $3 \mathrm{~h}$ of treatment might have resulted from its escape during continuous shaking of the wastewater.

Fertilizers and cattle manure are significant sources of nitrate contamination in wastewater. The measured values of nitrate and nitrite in the collected wastewater were calculated to $0.16 \mathrm{mg} / \mathrm{L}$ and $1.08 \mathrm{mg} / \mathrm{L}$, respectively. No significant change in the nitrate/nitrite concentration was observed upon biological treatment using HRP; nitrates and nitrites are mainly removed from wastewater using anaerobic bacteria like Pseudomonas species, which convert them to elemental nitrogen that is liberated to the atmosphere.

BOD is a measure of the organic pollution of water. It determines the amount of dissolved oxygen (mg of $\mathrm{O}_{2}$ consumed per liter of sample) needed by aerobic biological organisms to break down organic material present in a given water sample at certain temperature (e.g. $27^{\circ} \mathrm{C}$ ) over a specific time period (e.g. 3 days). Unlike BOD, the COD measures the oxygen required to oxidize all carbon compounds in a solution. BOD and COD values of phenol- spiked wastewater were measured before and after treatment. As shown in Table 2, the BOD value dropped from $208 \mathrm{mg} / \mathrm{L}$ to approximately $26 \mathrm{mg} / \mathrm{L}$ after enzymatic treatment, suggesting the $87 \%$ reduction in oxygen demand for biodegradation of organic pollutants. On the other hand, COD reduction of almost $77 \%$ was achieved upon treatment with immobilized HRP. Such observations are also reported by other authors [47, 48].

The significant decrease in BOD and COD values of treated spiked-wastewater demonstrated the effectiveness of the proposed method to transform phenolic into precipitable simpler compounds.

\subsection{Reusability and Storage Stability of Immobilized HRP}

The reusability of immobilized HRP in degradation of the phenolic compounds in sewage wastewater was studied using inverted mixture as described in section 2.9. As we observed $93 \%$ degradation in phenolic content in $2 \mathrm{~h}$ treatment, we therefore selected cycles of $2 \mathrm{~h}$ to investigate the efficiency of phenol removal by immobilized HRP. We found that after 4 cycles of phenol degradation, the efficiency of HRP get reduced to $60 \%$. However, this can be improved by quick washing of HRP-immobilized disc with MilliQ or respective buffer in order to remove the deposited phenolic precipitate and other contaminant which may interfere in enzyme-substrate interactions [12].

Furthermore, storage stability of immobilized HRP was investigated by storing the immobilized preparation of HRP in a sealed polythene bag in refrigerator at $4{ }^{\circ} \mathrm{C}$ for two weeks and thereafter studying the phenolic degradation. We found the immobilized HRP could fully retain its activity upon two week storages. This suggests that the immobilized enzyme could be stored at $4{ }^{\circ} \mathrm{C}$ for at least two weeks without loss of activity.

\section{Conclusions}

Direct discharge of industrial effluents enriched in toxic and carcinogenic phenolic pollutants to water bodies can pose a serious threat to human lives. This study investigates the effectiveness of immobilized HRP for phenol degradation in sewage wastewater. The present method reduced the total phenol concentration in sewage wastewater by $91-95 \%$. Beside dephenolization, the treated water showed 
overall improvement in quality as reflected by the $77 \%$ and $87 \%$ reduction of the COD and the BOD values, increased $\mathrm{pH}$ and reduced turbidity, dissolved salts concentration and nitrate and nitrite components. Phenols along with other biodegradable compounds were removed as precipitate from wastewater. PEG was used as a protective additive, which helped in retaining enzymatic activity of HRP by 2-3 folds. The results showed that the present approach could be effectively employed for the enzymatic treatment of phenols from industrial wastewater, making the treated water usable for agriculture and non-drinking anthropological activities.

\section{Acknowledgments}

The authors thank the Council of Scientific and Industrial Research grant CARDIOMED (BSC0122) and SERB- Department of Science and Technology, Government of India, for providing the financial support to this work. R. A. thanks the Council of Scientific and Industrial Research, Government of India for the award of a senior research fellowship. S. K. thanks SERB-DST, Government of India for the award of Fast Track Young Scientist.

\section{References}

[1] Liu, J. Z., Song, H. Y., Weng, L. P., and Ji, L. N. 2002. "Increased Thermostability and Phenol Removal Efficiency by Chemical Modified Horseradish Peroxidase." J. Mol. Catal., B Enzym. 18: 225-32.

[2] Asad, S., Dabirmanesh, B., and Khajeh, K. 2014. "Phenol Removal from Refinery Wastewater by Mutant Recombinant Horseradish Peroxidase.” Biotechnol. Appl. Biochem. 61: 226-9.

[3] Kurnik, K., Treder, K., Skorupa-Klaput, M., Tretyn, A., and Tyburski, J. 2015. "Removal of Phenol from Synthetic and Industrial Wastewater by Potato Pulp Peroxidases." Water Air Soil Pollut. 226: 254.

[4] Ikehata, K., Buchanan, I. D., and Smith, D. W. 2003. "Treatment of Oil Refinery Wastewater Using Crude Coprinus Cinereus Peroxidase and Hydrogen Peroxide." J. Environ. Eng. Sci. 2: 463-72.

[5] Baker, E. L., Landrigan, P. J., Bertozzi, P. E., Field, P. H., Basteyns, B. J., and Skinner, H. G. 1978. "Phenol Poisoning due to Contaminated Drinking Water." Arch. Environ. Health 33: 89-94.
[6] Cohen-Yaniv, V., and Dosoretz, C. G. 2009. "Fate of Horseradish Peroxidase during Oxidation of Monobrominated Phenols." J. Chem. Technol. Biotechnol. 84: 1559-66.

[7] Xu, Q., Li, X., Zhou, Y. E., Wei, H., Hu, X. Y., Wang, Y., and Yang, Z. 2012. "An Enzymatic Amplified System for the Detection of 2, 4-Dichlorophenol Based on Graphene Membrane Modified Electrode." Anal. Methods 4: 3429-35.

[8] Villegas, L. G. C., Mashhadi, N., Chen, M., Mukherjee, D., Taylor, K. E., and Biswas, N. 2016. "A Short Review of Techniques for Phenol Removal from Wastewater." Curr. Pollution Rep. 2: 157-67.

[9] Mohammadi, S., Kargari, A., Sanaeepur, H., Abbassian, K., Najafi, A., and Mofarrah, E. 2015. "Phenol Removal from Industrial Wastewaters: A Short Review." Desalination and Water Treatment 53: 2215-34.

[10] Kulkarni, S. J., and Kaware, D. J. P. 2013. "Review on Research for Removal of Phenol from Wastewater." International Journal of Scientific and Research Publications 3: 1-4.

[11] Bayramoglu, G., Akbulut, A., and Arica, M. Y. 2013. "Immobilization of Tyrosinase on Modified Diatom Biosilica: Enzymatic Removal of Phenolic Compounds from Aqueous Solution.” J. Hazard. Mater. 244-245 (2): 528-36.

[12] Cheng, J., Ming Yu, S., and Zuo, P. 2006. "Horseradish Peroxidase Immobilized on Aluminium-Pillared Inter-layered Clay for the Catalytic Oxidation of Phenolic Wastewater." Water Res. 40: 283-90.

[13] Jiang, Y., Tang, W., Gao, J., Zhou, L., and He, Y. 2014. "Immobilization of Horseradish Peroxidase in Phospholipid-Templated Titania and Its Applications in Phenolic Compounds and Dye Removal." Enzyme Microb. Technol. 55: 1-6.

[14] Cheng, W., and Harper Jr., W. F. 2012. "Chemical Kinetics and Interactions Involved in Horseradish Peroxidase-Mediated Oxidative Polymerization of Phenolic Compounds." Enzyme Microb. Technol. 50: 204-8.

[15] Li, H., Li, Y., Cao, H., Li, X., and Zhang, Y. 2011. "Degradation of Pentachlorophenol by a Novel Peroxidase-Catalyzed Process in the Presence of Reduced Nicotinamide Adenine Dinucleotide." Chemosphere 83: 124-30.

[16] Nazari, K., Esmaeili, N., Mahmoudi, A., Rahimi, H., and Moosavi-Movahedi, A. A. 2007. "Peroxidative Phenol Removal from Aqueous Solutions Using Activated Peroxidase Biocatalyst." Enzyme Microb. Technol. 41: 226-33.

[17] Pan, C., Ding, R., Dong, L., Wang, J., and Hu, Y. 2015. "Horseradish Peroxidase-Carrying Electrospun Nonwoven Fabrics for the Treatment of 


\section{A Simple and Efficient Method for Removal of Phenolic Contaminants in Wastewater Using Covalent Immobilized Horseradish Peroxidase}

o-Methoxyphenol." J. Nanomaterials 2015: 1-6.

[18] Zhang, L., Zhao, W., Chen, H., and Cui, Y. 2013. "Enzymatic Synthesis of Phenol Polymer and Its Functionalization.” J. Mol. Catal., B Enzym. 87: 30-6.

[19] Stanisavljevic, M., and Nedic, L. 2004. "Removal of Phenol from Industrial Wastewaters by Rseradish (Cochlearia Armoracia 1) Peroxidase." Working and Living Environmental Protection 2: 345-9.

[20] Spahn, C., and Minteer, S. D. 2008. "Enzyme Immobilization in Biotechnology." Recent Patents on Engineering 2: 195-200.

[21] Prodanovic, O., Prokopijevic, M., Spasojevic, D., Stojanovic, Z., Radotic, K., Knezevic-Jugovic, Z. D., and Prodanovic, R. 2012. "Improved Covalent Immobilization of Horseradish Peroxidase on Macroporous Glycidyl Methacrylate-based Copolymers." Appl. Biochem. Biotechnol. 168: 1288-301.

[22] Kondyurin, A. V., Naseri, P., Tilley, J. M., Nosworthy, N. J., Bilek, M. M., and McKenzie, D. R. 2012. "Mechanisms for Covalent Immobilization of Horseradish Peroxidase on Ion-Beam-Treated Polyethylene." Scientifica 2012: 1-28.

[23] Cao, X., Yu, J., Zhang, Z., and Liu, S. 2012. "Bioactivity of Horseradish Peroxidase Entrapped in Silica Nanospheres.” Biosens. Bioelectron. 35: 101-7.

[24] Lei, C. X., Hu, S. Q., Shen, G. L., and Yu, R. Q. 2003. "Immobilization of Horseradish Peroxidase to a Nano-Au Monolayer Modified Chitosan-Entrapped Carbon Paste Electrode for the Detection of Hydrogen Peroxide." Talanta 59: 981-8.

[25] Lin, T. Y., Wu, C. H., and Brennan, J. D. 2007. "Entrapment of Horseradish Peroxidase in Sugar-Modified Silica Monoliths: Toward the Development of a Biocatalytic Sensor." Biosens. Bioelectron. 22: 1861-7.

[26] Kumar, S., Kumar, D., Ahirwar, R., and Nahar, P. 2016. "Exploring the Flexible Chemistry of 4-Fluoro-3-Nitrophenyl Azide for Biomolecule Immobilization and Bioconjugation." Anal. Bioanal. Chem. 408: 6945-56.

[27] Shannon, L. M., Kay, E., and Lew, J. Y. 1966. "Peroxidase Isozymes from Horseradish Roots. I. Isolation and Physical Properties." J. Biol. Chem. 241 (9): 2166-72.

[28] Worthington, K., and Worthington, V. 2011. Worthington Enzyme Manual. Worthington: Biochemical Corporation.

[29] Buchanan, I. D., and Nicell, J. A. 1997. "Model Development for Horseradish Peroxidase Catalyzed Removal of Aqueous Phenol.” Biotechnol. Bioeng. 54: 251-61.

[30] Nahar, P., Wali, N. M., and Gandhi, R. P. 2001. "Light-induced Activation of an Inert Surface for
Covalent Immobilization of a Protein Ligand." Anal. Biochem. 294: 148-53.

[31] Smith, P. K., Krohn, R. I., Hermanson, G. T., Mallia, A. K., Gartner, F. H., Provenzano, M. D., Fujimoto, E. K., Goeke, N. M., Olson, B. J., and Klenk, D. C. 1985. "Measurement of Protein Using Bicinchoninic Acid." Anal. Biochem. 150: 76-85.

[32] Wu, Y., Taylor, K. E., Biswas, N., and Bewtra, J. K. 1998. "A Model for the Protective Effect of Additives on the Activity of Horseradish Peroxidase in the Removal of Phenol." Enzyme Microb. Technol. 22: 315-22.

[33] Zatar, N. A., Abu-Eid, M. A., and Eid, A. F. 1999. "Spectrophotometric Determination of Nitrite and Nitrate Using Phosphomolybdenum Blue Complex." Talanta 50: 819-26.

[34] Central Water Commission, G.o.I. 1999. "Standard Analytical Procedures for Water Analysis." CSMRS Building, 4th Floor, Olof Palme Marg, Hauz Khas, New Delhi-110016 (INDIA).

[35] Davies, H. M., and Manning, J. R. 2008. "Catalytic C-H Functionalization by Metal Carbenoid and Nitrenoid Insertion." Nature 451: 417-24.

[36] Bora, U., Sharma, P., Kumar, S., Kannan, K., and Nahar, P. 2006. "Photochemical Activation of a Polycarbonate Surface for Covalent Immobilization of a Protein Ligand." Talanta 70: 624-9.

[37] Prodanovic, O., Prokopijevic, M., Spasojevic, D., Stojanovic, Z., Radotic, K., Knezevic-Jugovic, Z. D., and Prodanovic, R. 2012. "Improved Covalent Immobilization of Horseradish Peroxidase on Macroporous Glycidyl Methacrylate-based Copolymers." Appl. Biochem. Biotechnol. 168: 1288-301.

[38] Masuda, Y., Kugimiya, S. I., and Kato, K. 2014. "Improvement of Thermal-Stability of Enzyme Immobilized onto Mesoporous Zirconia." Journal of Asian Ceramic Societies 2: 11-9.

[39] Temocin, Z., and Yigitoglu, M. 2009. "Studies on the Activity and Stability of Immobilized Horseradish Peroxidase on Poly(Ethylene Terephthalate) Grafted Acrylamide Fiber." Bioprocess Biosyst. Eng. 32: 467-74.

[40] Ai, J., Zhang, W., Liao, G., Xia, H., and Wang, D. 2016. "Immobilization of Horseradish Peroxidase Enzymes on Hydrous-Titanium and Application for Phenol Removal." RSC Advances 6: 38117-23.

[41] Mukhopadhyay, A., Dasgupta, A. K., and Chakrabarti, K. 2013. "Thermostability, pH Stability and Dye Degrading Activity of a Bacterial Laccase are Enhanced in the Presence of $\mathrm{Cu}_{2} \mathrm{O}$ Nanoparticles." Bioresource Technology 127: 25-36.

[42] Klibanov, A. M., Tu, T. M., and Scott, K. P. 1983. "Peroxidase-Catalyzed Removal of Phenols from Coal-Conversion Waste Waters." Science (New York, 

Wastewater Using Covalent Immobilized Horseradish Peroxidase

N.Y.) 221: 259-61.

[43] Nicell, J. A., Saadi, K. W., and Buchanan, I. D. 1995. "Phenol Polymerization and Precipitation by Horseradish Peroxidase Enzyme and an Additive." Bioresource Technology 54: 5-16.

[44] Nakamoto, S., and Machida, N. 1992. "Phenol Removal from Aqueous Solutions by Peroxidase-Catalyzed Reaction Using Additives." Water Research 26: 49-54.

[45] Mao, L., Luo, S., Huang, Q., and Lu, J. 2013. "Horseradish Peroxidase Inactivation: Heme Destruction and Influence of Polyethylene Glycol." Scientific Reports 3: 3126 .
[46] Tatsumi, K., Wada, S., and Ichikawa, H. 1996. "Removal of Chlorophenols from Wastewater by Immobilized Horseradish Peroxidase.” Biotechnol. Bioeng. 51: 126-30.

[47] Wagner, M., and Nicell, J. A. 2001. "Peroxidase-Catalyzed Removal of Phenols from a Petroleum Refinery Wastewater." Water Science and Technology: A Journal of the International Association on Water Pollution Research 43: 253-60.

[48] Bilal, M., and Asgher, M. 2015. "Dye Decolorization and Detoxification Potential of Ca-Alginate Beads Immobilized Manganese Peroxidase.” BMC Biotechnol. 15: 111 . 